\title{
Evaluation of Implementing Status of Diploma Nursing Curriculum in Bangladesh
}

\author{
Md. Humayun Kabir Talukder ${ }^{1}$, Md. Zakir Hossian ${ }^{2}$, Nasrin Akther ${ }^{3}$, Rumana Nazneen ${ }^{4}$ Ismat Ara \\ Perveen $^{5}$
}

\begin{abstract}
This descriptive type of cross-sectional study was conducted to evaluate the implementing status of diploma nursing curriculum in Bangladesh according to teachers' and students' views along with four specific objectives. The study was conducted at different government diploma nursing institutes of Bangladesh within July 2009 to June 2010. Teachers \& students of different diploma nursing institutes were the study population. Out of them as per the inclusion and exclusion criteria data were collected by simple random sampling. Self-administered structured questionnaire was used to collect data. Sample size was 1107 out of which 103 teachers and 1004 students. Study revealed that out of $1107,626(56.8 \%)$ respondents expressed that the present diploma nursing curriculum averagely will be able to fulfill the demand of the nursing profession. Most of the respondents 1001 (90.4\%) expressed their opinion that the present diploma nursing curriculum should be changed. 1088 (98.3\%) responded negatively that they do not get books as per need of the curriculum. 1084 (97.9\%) respondents replied negatively that they do not have sufficient teaching staff for implementing present diploma nursing curriculum. Around 583 (52.7\%) respondents replied negatively that examination are not conducted perfectly as per the present curriculum. $667(60.6 \%)$ respondents expressed about library, 609 (55.3\%) expressed about practical classes \& $785(71.3 \%)$ viewed about clinical training at hospital for better implementation of diploma nursing curriculum. Study recommended that the ongoing diploma nursing curriculum to be reviewed, updated considering the context of the country as well as need of the country, books to be developed/written as per the demand of present diploma nursing curriculum and should make those available. For better implementation of diploma nursing curriculum it was also recommended that number of the relevant teachers at different nursing institutes to be increased \& they should be oriented on revised updated diploma nursing curriculum, teaching methodology and evaluation or assessment of the students. For the improvement of present diploma nursing course admission policy, syllabus /course materials, teaching methods, evaluation/assessment, library, practical class and clinical training at hospitals to be changed and redesigned for the better interest of the country as well as for the nursing profession.
\end{abstract}

Key words: Evaluation, Implementing Status, Diploma nursing curriculum,

1Associate Professor, (CME), Mohakhali, Dhaka, ${ }^{2}$ Register, $S D C$, Dhaka

${ }^{3}$ Assistant Professor, SSMC,

${ }^{4}$ Assistant Professor, OBGYN, HFRC

${ }^{5}$ MPH Student, HE Dept, NIPSOM

\section{Introduction}

Knowledgeable, competent, attitudinally prepared, articulated and well co-ordinated health care team is an important pre-requisite for effective health care services ${ }^{1}$. A nurse in a health care team plays a pivotal role for smooth functioning of the team $^{2}$. Without the competent effort of a nurse health care delivery is practically meaningless. So, for effective delivery of health care services in terms of preventive, promotive, rehabilitative and curative care, competent nurse in a health care team is very essential ${ }^{3}$. At present in Bangladesh 46 government diploma nursing institutes are enrolling 1850 students each year as per the BNC approved nursing curriculum ${ }^{4}$. Curriculum planning and designing is not static process, rather a continuous process done regularly through a system ${ }^{5}$. This new diploma nursing curriculum was developed and designed scientifically, which was responsive to the needs of the learners and was consumer focused ${ }^{6}$. This diploma nursing curriculum was implemented with the newly admitted students from the sessions 2004-2005. It was hope that this curriculum will serve as guidelines for the students and faculty members. In conclusion it could be said that the curriculum planning process should be continuous, dynamic and never-ending. So it is important to evaluate the implementing status of diploma nursing curriculum in Bangladesh whether it is in the right track or not, what are the major constraints or barrier for it's effective implementation. The findings of the evaluation will help to overcome those to get optimum benefit of this diploma nursing curriculum.

\section{Rationale}

Diploma nursing curriculum was reviewed and updated in 2004 to develop the competent nurses adopting the primary health care approach. With these diploma curriculum Bangladesh Nursing Council (BNC) is providing diploma in nursing through different nursing institutes. This curriculum was being practiced for last five years but it was not evaluated in what extent the curriculum is being implemented. This study was designed to evaluate the implementation status of 
curriculum of diploma nursing course. Finding of this study will help to identify the present implementing status and gaps between expectation and actual status of diploma nursing education, which will ultimately help for better implementation of diploma nursing curriculum and also for it's reviewing \& updating.

\section{General Objective}

To assess the implementing status of diploma nursing curriculum in Bangladesh.

\section{Specific Objective}

1. To assess how the teachers are perceiving about the ongoing diploma nursing curriculum

2. To assess how the students are perceiving about the existing diploma nursing curriculum

3. To find out the gaps between expectation and actual implementing status of diploma nursing curriculum.
4. To identify the constraints for implementing diploma nursing curriculum in Bangladesh.

\section{Materials \& Methods}

This was a descriptive type of cross sectional study it was conducted at different government diploma nursing institutes of Bangladesh. Study period was July 2009 to June 2010. Study population were the students and teachers of nursing institutes fulfilling inclusion and exclusion criteria. Sampling technique was simple random sampling. Sample Size was 1107 (Students 1004, \& Teachers 103). Pre-tested self-administered structured questioner was used for data collection. Focus Group Discussion (FGD) was also conducted to collect indepth information with teachers, policy makers about the implementing status of diploma nursing curriculum of Bangladesh. Prior permission was taken from the concerned authorities. Consent was taken from the respondents. Confidentiality and anonymity of the respondents were maintained.

\section{Results}

Table 1 : Distribution of the respondents by their opinion regarding their comments about the present diploma nursing curriculum

\begin{tabular}{|l|c|c|c|}
\hline \multirow{2}{*}{$\begin{array}{c}\text { Comments about present } \\
\text { diploma nursing curriculum }\end{array}$} & \multicolumn{3}{|c|}{ Respondents } \\
\cline { 2 - 4 } & Students \& Teacher & Only Teachers & Only Students \\
\hline Very good & $106(9.6 \%)$ & $18(17 \%)$ & $88(9 \%)$ \\
\hline Good & $387(35.0 \%)$ & $9(9 \%)$ & $378(38 \%)$ \\
\hline Average & $548(49.5 \%)$ & $74(72 \%)$ & $474(46 \%)$ \\
\hline Low quality & $18(1.6 \%)$ & $0(0 \%)$ & $18(2 \%)$ \\
\hline Very bad & $48(4.3 \%)$ & $2(2 \%)$ & $46(5 \%)$ \\
\hline Total & $1107(100 \%)$ & 103 & 1004 \\
\hline
\end{tabular}

Graph 1 : Distribution of the respondents by their opinion about the extent to which the present diploma nursing curriculum will be able to fulfill the demand of the nursing profession

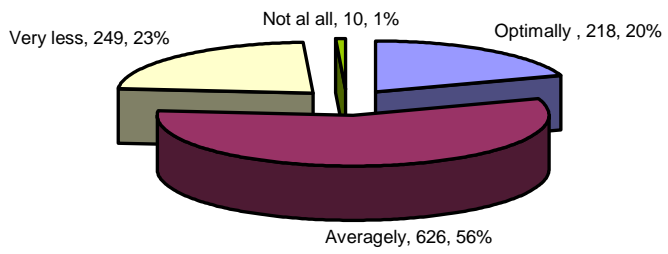


Table 2 : Distribution of the respondents by their opinion whether the present diploma nursing curriculum should be changed or not

\begin{tabular}{|c|c|c|}
\hline Different opinions about present diploma nursing curriculum & Yes & No \\
\hline Present diploma nursing curriculum should be changed & $\begin{array}{l}10001 \\
(90.4 \%)\end{array}$ & $106(9.6 \%)$ \\
\hline $\begin{array}{l}\text { Students \& teachers get books as per the demand of the present diploma } \\
\text { nursing curriculum }\end{array}$ & $\begin{array}{l}19 \\
(1.7)\end{array}$ & $\begin{array}{c}1088 \\
(98.3 \%)\end{array}$ \\
\hline Teaching staff' is sufficient to implement present diploma nursing curriculum & $23(2.1 \%)$ & $\begin{array}{c}1084 \\
(97.9 \%)\end{array}$ \\
\hline $\begin{array}{l}\text { The examinations are being conducted perfectly as per present diploma nursing } \\
\text { curriculum }\end{array}$ & $\begin{array}{c}524 \\
(47.3 \%)\end{array}$ & $\begin{array}{c}583 \\
(52.7 \%)\end{array}$ \\
\hline
\end{tabular}

Graph 2: Distribution of the respondents by their opinion, up to which extent the change of diploma nursing curriculum is needed

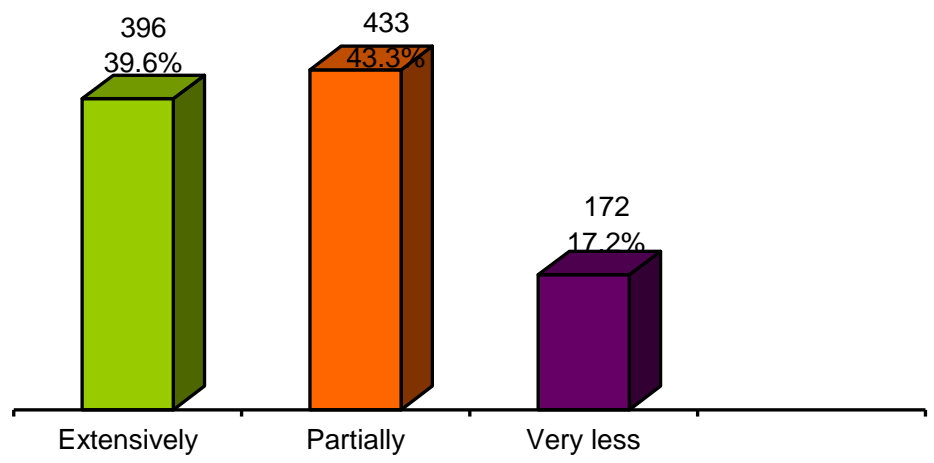

Table 3 : Distribution of the respondents as per their opinion in which areas of present diploma nursing curriculum should be changed for it's improvement

\begin{tabular}{|l|c|c|}
\hline $\begin{array}{c}\text { Areas of present diploma nursing } \\
\text { curriculum in which changes are } \\
\text { needed }\end{array}$ & Frequency & $\%$ \\
\hline Admission policy & 591 & 59.0 \\
\hline Syllabus/course materials & 698 & 69.7 \\
\hline Teaching methods & 388 & 38.7 \\
\hline Evaluation/Assessment system & 488 & 48.7 \\
\hline Library & 667 & 60.6 \\
\hline Lecture class & 196 & 17.8 \\
\hline Practical class & 609 & 55.3 \\
\hline Tutorial class & 271 & 24.6 \\
\hline Student-teacher relation & 176 & 16.0 \\
\hline Hostel & 403 & 36.6 \\
\hline Clinical training at hospital & 785 & 71.3 \\
\hline Others & 277 & 25.2 \\
\hline
\end{tabular}

* Responses are more than $100 \%$ due to multiple response 


\section{Focus Group Discussion (FGD)}

FGD revealed that the present ongoing diploma nursing curriculum to be reviewed, updated considering the context of the country as well as the need of the country. It was also recommended

\section{Discussion}

There are shortage of teachers at most of the diploma nursing institutes which was also reflected during data collection. On the other hand government is increasing number of students as per the demanding need of nurses with in the country and as well as outside Bangladesh. Though few of the respondents expressed the present diploma nursing curriculum at different positive level but more than $50 \%$ respondents viewed negatively about the present diploma nursing curriculum. Apart from that few of the respondents straight way expressed their views that this present diploma nursing curriculum will not be able to fulfill the demand of the nursing profession. Nearly all the respondents expressed that this present diploma nursing curriculum should be changed. As different subjects/disciplines of this present diploma nursing curriculum are very high level, which sometimes do not fit with our country context.

Shortage of teaching staff and unavailability of books due to rare contents/subjects are being considered as major problems for implementing the present diploma nursing curriculum. There is a provision of licensing examination by BNC. Conceptually though it is a good initiative but country context to be taken in to consideration. Perhaps these crucial factors leaded the respondents to change the present diploma nursing curriculum extensively to make it more user friendly considering country need and context. These problems should be addressed properly. More than fifty percentage of the teachers expressed that examinations are not being conducted perfectly as per the principles of assessment. As within the present diploma nursing curriculum there is no provision of examinations under the supervision and monitoring of Bangladesh Nursing Council (BNC) like before. As per the present diploma nursing curriculum local teachers of the nursing institutes are responsible to plan, design, conduct the examinations and also to publish the results locally. But on reality all the nursing institutes having a strong limitation of shortage of teachers or scarcity of teachers. In such a situation it is difficult to perform the examinations procedures which were reflected by the respondents responses. Obviously the present diploma nursing curriculum has lot of innovative ideas, contents, procedures than the previous curriculum which was reflected by respondents responses though the present curriculum does not fit with Bangladesh context. by FGD that books to be developed/written as per the demand of present diploma nursing curriculum and should make those available for the students as well as for the teachers with central system of student assessment.

Study strongly revealed that for better, effective and competent implementation of the present diploma nursing curriculum few areas/events to be addressed properly. Those areas and events are such as- admission policy, syllabus/course materials, library, practical classes and clinical training at hospitals.

\section{Recommendations}

Study recommended that the present ongoing diploma nursing curriculum to be reviewed, updated considering the context of the country as well as the need of the country, number of the relevant teachers at different nursing institutes to be increased, teachers of the nursing institutes should be oriented on revised updated diploma nursing curriculum, teaching methodology and evaluation or assessment of the students. It was also recommended that for the improvement of the implementing status of ongoing diploma nursing curriculum admission policy, syllabus /course materials, teaching methods, evaluation/assessment, library, practical class and clinical training at hospitals to be changed and redesigned, books to be developed/written as per the present diploma nursing curriculum and should make those books available for the students as well as for the teachers, To maintain standard, uniformity and transparency students assessment should be centrally planned, designed, conducted \& evaluated through a third party like as before which was conducted by BNC with a central co-ordinated mechanism.

\section{References}

1. Bangladesh Nursing Council. BSc in Nursing Curriculum, 2007

2. DGHS (2007b) A Report on Expansion of Medical Education for Balanced Production of Health Workforce. Dhaka, Directorate General of Health Services (DGHS) and Ministry of Health and Family Welfare.

3. DGHS (2007a) Report of the Committee to Determine the Work Plan of Current and Future Status of Post-Graduate Medical Education. Directorate General of Health Services (DGHS) and Ministry of Health and Family Welfare. (Bengali)

4. MOH\&FW. GO on BSc \& Diploma Nursing Institutes \& Seats Distribution, 2009

5. Talukder Humayun Kabir. Process of Curriculum Development, CME News Letter, 2002.

6. Bangladesh Nursing Council. Diploma in Nursing Curriculum, 2004 